\title{
Hormonal Changes in Relation to Productivity of Pregnant Rabbit Does
}

\author{
Gamal Ashour ${ }^{1}$ and Samah Mohamed Abdel-Rahman ${ }^{2 *}$ \\ ${ }^{1}$ Animal Production Department, Faculty of Agriculture, Cairo University, 12613 Giza, Egypt \\ ${ }^{2}$ Animal Production Research Institute, Agricultural Research Center, Nadi El-Said Street, Dokki, Egypt \\ *Corresponding author`s Email: samah.abdelrahman@yahoo.com
}

\begin{abstract}
Pregnancy is a critical period for animals where it undergoes many physiological changes including hormones, which are not received a great attention in rabbit. Therefore, a total number of $25 \mathrm{New}$ Zealand White pregnant rabbit does were used, to assess the changes in concentration of relevant hormones in relation to rabbit productivity. Blood samples were collected on 14, 21 and 28 days of pregnancy and on kindling day to quantify six maternal hormones. Litter size and weight, in addition to average of weekly and total milk yield were determined. Concentrations of the six hormones during the second half of pregnancy ranged between 3.2 to $4.0 \mathrm{ng} / \mathrm{ml}$ for progesterone (P4), 47.3 to $89.0 \mathrm{pg} / \mathrm{ml}$ for estrogen (E2), 2.0 to $3.7 \mathrm{ng} / \mathrm{ml}$ for prolactin (PRL), 114.5 to $136.8 \mathrm{ng} / \mathrm{ml}$ for insulin like growth factor-I (IGF-I), 36.0 to $39.2 \mathrm{ng} / \mathrm{ml}$ for thyroxine (T4) and 1.9 to $2.2 \mathrm{ng} / \mathrm{ml}$ for triiodothyronine (T3). The corresponding values on kindling day were $1.6 \mathrm{ng} / \mathrm{ml}, 26.8 \mathrm{pg} / \mathrm{ml}, 4.6 \mathrm{ng} / \mathrm{ml}, 131.6$ $\mathrm{ng} / \mathrm{ml}, 37.4 \mathrm{ng} / \mathrm{ml}$ and $0.9 \mathrm{ng} / \mathrm{ml}$, respectively. At day 14, maternal P4, E2, PRL, T4 and T3 were the lowest, whereas IGF-I was the highest compared to the other two days of pregnancy. At day 28, levels of E2, PRL, T4 and T3 were the highest in comparison with days 14 and 21 of pregnancy. On kindling day, P4 and T3 showed the minimal levels, whilst PRL exhibited the maximal level compared to the levels at all the gestational days. The relationship among the different hormones had various trends. The average of total milk yield (129.9 g/d) was negatively correlated with both P4 and E2, and positively associated with the PRL, IGF-I, T4 and T3 hormones. Furthermore, litter size was positively related with P4, E2 and PRL, and negatively with T4, T3 and IGF-I. Whereas, litter weight was negatively correlated with P4, E2 and T4. We recommend giving more attention to the rabbit doe reproduction, particularly close to parturition to achieve good economical return. However, further studies are urgently needed in this area.
\end{abstract}

Key words: Hormones, Litter size, Litter weight, Milk production, Pregnancy, Rabbits

\section{INTRODUCTION}

In developing countries, rabbit production may play an important role in surmounting meat shortage especially that, rabbit's meat is characterized by highly nutritive value including low fat, cholesterol and increased protein level (Wahab et al., 2016). Despite of this distinctiveness, rabbit farming in Egypt is facing many constraints such as diseases, heat stress and poor feed quality (Ashour et al., 2018). Therefore, to improve this valuable industry, rabbit breeders need to understand their reproductive biology that considered fundamental step in rabbit farming success (Ashour et al., 2018).

During pregnancy, the endocrine network has an important and vital role in coordination of mammary gland (MG) development and the reproductive state of the animal (Neville et al., 2002). Through its direct action on MG development via the reproductive hormones (Progesterone; P4, Estrogen; E2 and Prolactin; PRL) (Neville et al., 2002) and indirect action through the metabolic hormones, such as thyroid hormones, that alter MG responsiveness to reproductive hormones and regulate milk synthesis (Neville et al., 2002).

Additionally, these hormones working on maintaining the pregnancy, this critical period needs the network of endocrine system (P4, E2, etc.) and the availability of the nutrient (lipids, glucose and proteins) to be continued successfully. The P4 hormone play a vital role during early and late pregnancy through its actions on implantation, myometrium and may regulate cytokine network in the uterus (González-Mariscal et al., 2009) Prior to labor, P4 tended to decrease meanwhile E2 increases to stimulate synthesis of prostaglandin (González-Mariscal et al., 2009). During late pregnancy in rabbits, the changes in P4, E2 and PRL levels are controlling the nest building to prepare the MG to nurse the newborn litter (González-Mariscal et al., 2009). Additionally, Insulin-Like Growth Factor -I (IGF-I) has an important role in the fetal growth and maternal metabolism during pregnancy. Thereby, regulating the availability of nutrient that required for the fetus growth (Sferruzzi-Perri et al., 2011). From the fore-mentioned studies, it is clear that several hormones are strongly interacted together in controlling reproductive functions, energy balance, growth and metabolism (Sferruzzi-Perri et al., 2011). However, the endocrinology of rabbit reproductive physiology is not received great attention (González-Mariscal et al., 2009). Nevertheless, the higher reproductive efficiency of rabbit does need 
further understanding of all possible physiological mechanisms that regulate reproduction. So, the hormonal profiles should be examined either individually or in a relation to one another.

\section{MATERIALS AND METHODS}

\section{Ethical approval}

The present work has been conducted in accordance with guidelines of the ethical committee of Faculty of Agriculture - Cairo University, in cooperation with Animal Production Research Institute, Agricultural Research Center. The experimental fieldwork was carried out at rabbitry unit of Animal Physiology Laboratory. Whereas, the hormonal analyses were executed at Cairo University Research Park, Faculty of Agriculture, Egypt.

\section{Experimental animals and diets}

A total number of 25 New Zealand White (NZW) rabbit does were checked for pregnancy (using hand palpation on the abdominal area) at day 14 after natural insemination. The pregnant does aged between 7-8 months with average body weight (BW) of 3252.58 $\pm 18.60 \mathrm{~g}$ were used. Before starting the experiment, the does were put in individual cages with males and naturally mated. After that, they were checked for pregnancy (at day 14) which was considered the beginning of the experiment. The pregnant does were healthy and we did not notice any abnormal signs (such as scabies or inactive movement). The experiment started at mid of gestation and lasted until the weaning age of the kits. The animals were housed individually in galvanized wire batteries in well-ventilated indoor pens, and providing them ad libitum feed (fed commercial pelleted diet). The fresh and clean water was available during the experiment. The rations (Table 1) satisfied the nutrient requirements of the does during pregnancy and lactation according to Lebas (2004).

Table 1. Feed ingredients and chemical analysis of the basal diet (\% dry matter basis) provided to the pregnant does during the experimental period

\begin{tabular}{ll|lc}
\hline Feed Ingredient & $(\boldsymbol{\%})$ & Chemical analysis (\%DM basis) & 89.00 \\
\hline Soybean meal (44\% CP) & 8.50 & Dry matter & 90.88 \\
Barley & 30.0 & Organic matter & 18.00 \\
Yellow corn & 9.50 & & 10.60 \\
Wheat bran & 23.0 & Crud protein & \\
Clover hay & 16.0 & Crud fiber & 2.50 \\
Corn gluten (60\%CP) & 9.70 & & 59.78 \\
Molasses & 0.30 & Ether extract & 9.12 \\
Limestone & 1.50 & Nitrogen free extract & 0.98 \\
Di- calcium phosphate & 0.50 & Ash & 0.70 \\
DL-Methionine & 0.20 & Lysine & 0.95 \\
Sodium chloride & 0.30 & Methionine+ cystene & 0.64 \\
Vit.-Min. premix & 0.30 & Calcium & 2750 \\
Anti-coccidiosis & 0.10 & Phosphorus & Digestible energy(kcal/kgDM) \\
Anti-Fungi & 0.10 & & \\
Total & 100 & & \\
\hline
\end{tabular}

${ }^{\mathrm{a}}$ Each $1 \mathrm{~kg}$ contain contains: $12000 \mathrm{IU}$ vit.A; $2200 \mathrm{IU}$ vit. D3; $13.4 \mathrm{mg}$ vit. E (determined); $2.0 \mathrm{mg}$ vit. K3; $1.0 \mathrm{mg}$ vit. B1; $4.0 \mathrm{mg}$ vit. B2; $1.5 \mathrm{mg}$ vit. B6; $0.0010 \mathrm{mg}$ vit. B12; $6.7 \mathrm{mg}$ vit. pantothenic; $6.67 \mathrm{mg}$ vit. B5; $0.07 \mathrm{mg} \mathrm{B8;} 1.67 \mathrm{mg}$ B9; $400 \mathrm{mg}$ choline chloride; $133.4 \mathrm{mg}$ Mg; $25.0 \mathrm{mg}$ Fe; 22.3 $\mathrm{mg} \mathrm{Zn;} 10.0 \mathrm{mg} \mathrm{Mn;1} \mathrm{.67} \mathrm{mg} \mathrm{Cu;} 0.25 \mathrm{mg}$ I and 0.033 mg Se, DM = Dry Matter, CR = Crude Protein

\section{Blood sampling and plasma hormonal analyses}

From the vena behind the rabbit does ear, about $3 \mathrm{ml}$ of blood samples were collected from each doe at pregnancy days (14, 21 and 28, Figure 1) and on kindling day. We choose these specific pregnancy days, because rabbit placentation is occurred at the day 13 and fetal growth occurred from the days 21 to 28 of pregnancy according to Wahab et al. (2016). The samples were collected in heparinized tubes and were centrifuged at $3000 \mathrm{rpm}$ for 20 minutes to get blood plasma that stored under $-20^{\circ} \mathrm{C}$ until hormonal analyses, which have been done according to the manufacturer procedure. In blood plasma, we assayed hormones, P4, E2, IGF-I, T4 and T3 using ELISA kits obtained from Sino Gen Clon Biotech, No.9 BoYuan Road, YuHang District 311112, HangZhou, China. While, PRL hormone was determined by using ELISA kit from Glory Science Co. (G1725, USA). The measured hormones P4, PRL, IGF-I, T4 and T3 are expressed in nanogram per milliliter $(\mathrm{ng} / \mathrm{ml})$ except the E2, which expressed in picogram per milliliter (pg/ml). Hormones were quantified by using a specific antibody for each hormone, which make solid phase. The combine hormone antibody with labeled horseradish peroxidase to form antibody-antigen-enzyme-antibody complex. After many steps and forming the blue color, the stop solution added and the color change is measured spectrophotometrically at wave length $450 \mathrm{~nm}$. 


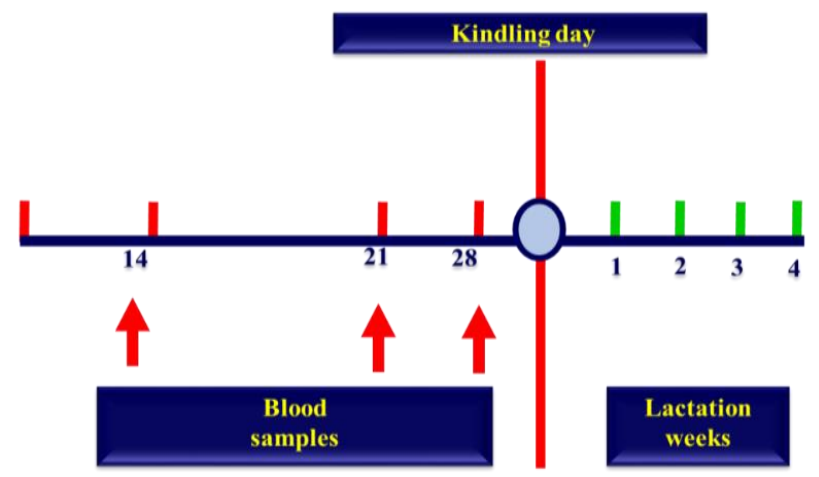

Figure 1. Time of collecting blood samples during gestation days and kindling day in New Zealand White rabbits.

\section{Body weights, litter size and milk production}

The litter weights were recorded concurrently with collecting milk samples to determine the amount of produced milk (daily milk yield, DMY g/d) by calculating the difference in kit's body weight before and after suckling. The dams continued in lactation for four weeks and the average of total milk yield (TMY, g/d) was calculated.

\section{Statistical analyses}

The collected data were subjected to one-way analysis of variance to detect the effects of time of collecting blood samples (sample date, SD) on hormonal changes during gestation period and its impact on subsequent lactation, litter size and weight, using the General Linear Model (GLM) procedure of XLSTAT (2018).

The statistical model used was as follows: $Y_{i j}=\mu+S_{i}+e_{i j}$. Where: Yijk= the individual observation, $\mu=$ the overall mean, $\mathrm{SD}_{\mathrm{i}}=$ the effect of time $(\mathrm{i}=1,2,3,4), \mathrm{e}_{\mathrm{ij}}=$ random error associated with the individual.

The differences among time means were separated according to Duncan's multiple range test (Duncan, 1955). The significance level was set at $5 \%(\mathrm{P}<0.05)$, and the correlation coefficient among hormones, milk yield, litter size and weight at birth was calculated.

\section{RESULTS AND DISCUSSION}

\section{Hormonal changes in pregnant rabbit does}

Progesterone hormone: As shown in table 2 and figure 2, P4 level at the mid of gestation was gradually increased reaching to the highest level $(4.00 \mathrm{ng} / \mathrm{ml})$ at day 21 of pregnancy. Then, decreased slightly prior to labor by two days. However, the differences among gestation days were insignificant $(\mathrm{P}>0.05)$. Thereafter, a drop and rapid reduction in $\mathrm{P} 4$ level have been recorded at delivery day. It could be noticed that, this level at kindling day was markedly and significantly $(\mathrm{P}<0.05)$ differed than that at all gestational days. In the present study, the level of $\mathrm{P} 4$ during the second half of pregnancy (14 - 28 days) is ranged between 3.16 to $4.00 \mathrm{ng} / \mathrm{ml}$. This finding agree with that of Kelden et al. (2017) who found that $\mathrm{P} 4$ level was $3.1 \mathrm{ng} / \mathrm{ml}$ during pregnancy period in rabbits.

In contrast, our values of P4 level are lower than those reported in other studies. González-Mariscal et al. (2009) found that the maximal level was observed on day $14(11 \pm 3 \mathrm{ng} / \mathrm{ml})$ after which $\mathrm{P} 4$ concentration gradually declined. Szendro et al. (2010) reported that P4 level was $9.4 \mathrm{ng} / \mathrm{ml}$ in pregnant rabbits. Also, Kirat et al. (2015) observed that P4 level at $10^{\text {th }}, 20^{\text {th }}$ and $30^{\text {th }}$ days of pregnancy were $9.9,5.3$ and $4.1 \mathrm{ng} / \mathrm{ml}$, respectively. Additionally, the present data disagree and lower than those of Alfonso (2016) who found that, the highest level (12 ng/ml) of P4 was at day 14 of pregnancy, after that its level started to decrease at days 21 and 28 of pregnancy (10 and $8 \mathrm{ng} / \mathrm{ml}$, respectively). On the other side, it is much higher than that $(1.5 \mathrm{ng} / \mathrm{ml})$ obtained by Bostanci et al. (2012). Generally, the level of P4 hormone in rabbits during pregnancy is lower than that in other species, Neville et al. (2002) stated that P4 in rat is ranged between 6-130 $\mathrm{ng} / \mathrm{ml}$, and reaching to $200 \mathrm{ng} / \mathrm{ml}$ in human.

These contradicted results concerning the changes in P4 levels and patterns in the above mentioned studies could be attributed to many factors particularly genetic makeup, parity, managerial and environmental conditions. It is well known that P4 level in rabbits remain high throughout pregnancy period (Szendro et al., 2010). This elevation in P4 level is essential for both, the first wave of MG differentiation, which called lactogenesis 1 that starting at mid-gestation and alveolar proliferation (Neville et al., 2002). Furthermore, it is essential for the maintenance of pregnancy in rabbits and is crucial for keeping the uterus in a quiescent state to prevent premature onset of labor (Kirat et al., 2015). Also, it helps the fetus implantation and maintain continuation of pregnancy (Kelden et al., 2017). 
Table 2. Hormonal changes during the second half of gestational days and at kindling day in New Zealand White rabbit does

\begin{tabular}{lcccc}
\hline $\begin{array}{l}\text { Hormones } \\
\text { (ng/ml) }\end{array}$ & \multicolumn{3}{c}{ Pregnancy days } & \multirow{2}{*}{ Delivery day } \\
\cline { 2 - 4 } P4 & $\mathbf{1 4}$ & $\mathbf{2 1}$ & $\mathbf{2 8}$ & $1.58 \pm 0.30^{\mathrm{a}}$ \\
E2 (pg/ml) & $3.16 \pm 0.30^{\mathrm{b}}$ & $4.00 \pm 0.32^{\mathrm{b}}$ & $3.94 \pm 0.32^{\mathrm{b}}$ & $26.75 \pm 4.99^{\mathrm{a}}$ \\
PRL & $47.31 \pm 4.99^{\mathrm{b}}$ & $56.33 \pm 5.34^{\mathrm{b}}$ & $88.99 \pm 5.34^{\mathrm{c}}$ & $4.64 \pm 0.75^{\mathrm{b}}$ \\
IGF-I & $1.97 \pm 0.75^{\mathrm{a}}$ & $2.35 \pm 0.80^{\mathrm{ab}}$ & $3.68 \pm 0.80^{\mathrm{ab}}$ & $131.57 \pm 6.77^{\mathrm{b}}$ \\
T4 & $136.81 \pm 6.77^{\mathrm{b}}$ & $114.46 \pm 7.33^{\mathrm{a}}$ & $118.69 \pm 7.33^{\mathrm{ab}}$ & $37.41 \pm 1.82$ \\
T3 & $36.00 \pm 1.72$ & $38.28 \pm 1.82$ & $39.20 \pm 1.82$ & $0.91 \pm 0.12$ \\
\hline
\end{tabular}

$\overline{\mathrm{a}, \mathrm{b}, \mathrm{c}}$ Means in the same row with different superscripts are significantly different $(\mathrm{P}<0.05), \mathrm{P} 4=$ progesterone hormone; E2 $=\mathrm{Estrogen}$ hormone; $\mathrm{PRL}=$ Prolactin hormone; IFG-I= Insulin like growth factor-I; T4 = Thyroxine; T3 = Triiodothyronine

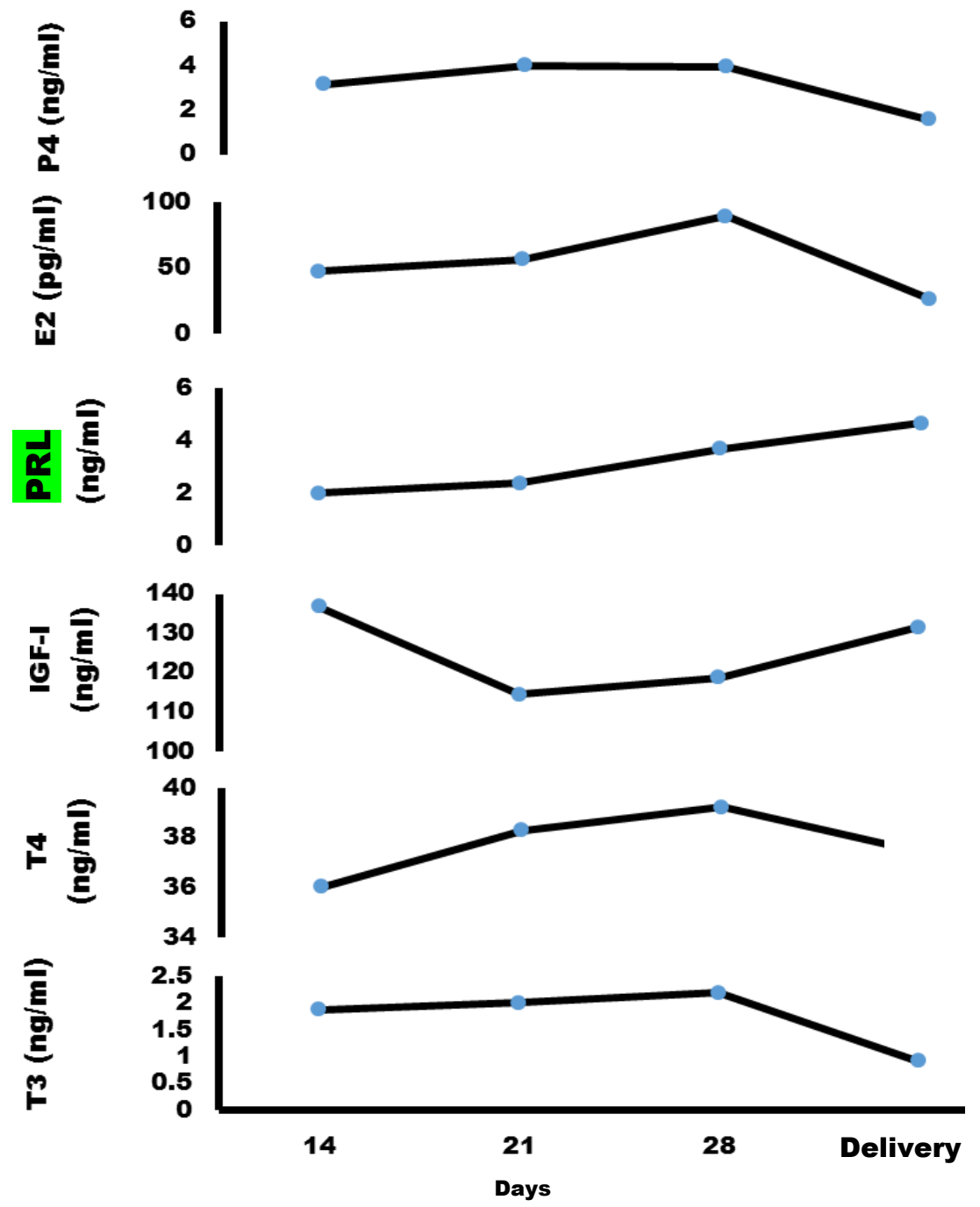

Figure 2. Hormonal changes during the second half of gestational days and at kindling day in New Zealand White rabbit does.

Estrogen hormone: During the second half of pregnancy days, E2 level increased progressively (Table 2 and Figure 2). It was significantly $(\mathrm{P}<0.05)$ increased overall the pregnancy days from the lowest level at day 14 to day 21 and continuing in increasing reaching to the highest level at day 28 before kindling. At day 28 of pregnancy, E2 level was markedly higher $(\mathrm{P}<0.05)$ than that at the previous levels at 14 and 21 days, which showed no significant $(\mathrm{P}>0.05)$ differences between them. This pattern of changes is similar to those reported by Al-Atawi et al. (2004) and Kirat et al. (2015).

Before labor by two days at day 28, E2 level obviously increased, whereas, P4 level slightly decreased. During pregnancy days, it could be noticed that the lowest levels of P4 and E2 were observed at day 14. Meanwhile, the highest levels were obtained at day 21 for P4 and at day 28 for E2 levels. Whereas, at delivery day, E2 level dramatically dropped $(\mathrm{P}<0.05)$ to lower level than that at all gestational days (Table 2). Nevertheless, both P4 and E2 levels showed 
the minimal values at kindling day than those at days of pregnancy. These findings are in harmony with that of Garfield et al. (1998) who stated that, in rabbits, the corpus luteum is the major source of peripheral P4 and parturition is preceded by luteolysis and a sudden P4 withdrawal with a concomitant increase in E2.

The current level is ranged between 47.3 to $89.0 \mathrm{pg} / \mathrm{ml}$ during the second half of pregnancy days. This level is slightly lower than that $(98.1 \mathrm{pg} / \mathrm{ml})$ found by Bostanci et al. (2012). Conversely, our present level is much higher than other studies. González-Mariscal et al. (2009) reported that this level in pregnant does was $24 \pm 6 \mathrm{pg} / \mathrm{ml}$ on pregnancy 21 d. In addition, Kirat et al. (2015) showed levels of 5.5, 10.5 and $16.8 \mathrm{pg} / \mathrm{ml}$ on days 10, 20 and 30, respectively of rabbit pregnancy.

Both P4 and E2 have synergistic relationship, as confirmed in the present study by their positive correlation $(+0.69$; $\mathrm{P}<0.05)$, because during the second half of rabbit pregnancy the luteal P4 synthesis is dependent upon the E2 level. This means that E2 is considered a vital factor in maintaining P4 level during gestation period (Bostanci et al., 2012). Furthermore, Neville et al. (2002) found that, E2 stimulates P4 receptors in the luminal epithelial cells of MG. However, it has negative impact on milk production, because E2 accelerate MG involution. In the same context, Bostanci et al. (2012) mentioned that both P4 and E2 are important in maintaining uterine via regulation of blood flow and synthesis of cell surface receptors. Additionally, they cleared that E2 may indirectly influences the antioxidant system, thereby reducing the free radicals that caused oxidative stress, but the way of interacting of E2 and the antioxidant system is not yet clear.

Prolactin hormone: As seen in table 2 and figure 2, level of PRL hormone showed a continuous and pronounced increase during the studied gestational days. It was insignificantly $(\mathrm{P}>0.05)$ increased from the lowest level at day 14 to the highest level at day 28. There were no significant $(\mathrm{P}>0.05)$ differences among the three times of gestation. During the second half of pregnancy days, maternal PRL level showed the same pattern of E2, both hormones continuously increased to reach the maximum values at day 28. Meanwhile, at that day P4 hormone started to decrease. This means that P4 and PRL hormones had a negative relationship $(-0.46 ; \mathrm{P}<0.05)$ as recorded in the present study.

On kindling day, PRL hormone substantially increased to reach to the maximal level. This level was greatly higher than that at all the gestational days. This increase was significant $(\mathrm{P}<0.05)$ in comparison with the level at day 14 and insignificant $(\mathrm{P}>0.05)$ with that at 21 and 28 days. The trend was opposite to that of both $\mathrm{P} 4$ and E2 hormones, they were lower at delivery day than the other days of gestation (Figure 2). During the second half of pregnancy, PRL is ranged between 2.00 to $3.7 \mathrm{ng} / \mathrm{ml}$. This concentration is higher than that $(1.97 \mathrm{ng} / \mathrm{ml}$ ) obtained by Kelden et al. (2017) in pregnant rabbits. Fortun et al. (1999) stated that, P4 levels were lower in lactating - pregnant rabbits than pregnant only without lactation. Moreover, they attributed these results to the increased level of PRL (Hyperprolactinemia) in the lactating - pregnant groups, which leads to inhibit P4 secretion. Additionally, suckling caused oxytocin release (has luteolytic role) which caused inhibition in P4 secretion. Also, they mentioned that, when the rabbits are pregnant and lactating at the same time, they consume more feed which have negative impact on P4 secretion. Level of PRL during gestation is essential for the second phase of MG differentiation (lactogenesis 2). This phase beginning around parturition, to prepare MG for colostrum secretion and then milk. In rats, a surge of PRL was reinitiated before labor by 24 h (Neville et al., 2002).

Insulin like growth factor - I: Concerning the IGF-I concentration during the second half of pregnancy, it was declined $(\mathrm{P}<0.05)$ from the highest level at day 14 to the lowest level at day 21 . It is clear that, this hormone reduced in the trimester than that at mid gestation. There were no significant $(\mathrm{P}>0.05)$ differences in its level between days 21 and 28 (Table 2 and Figure 2). This reduction in IGF-I in late pregnancy is important to reduce maternal anabolic activity to increase the availability of nutrients and deliver to the uterus (Sferruzzi-Perri et al., 2011). These changes in IGF-I concentrations are in harmony with Sferruzzi-Perri et al. (2011) who mentioned that, IGF-I in rabbit increased during the first half of pregnancy that caused by the increases of mRNA expression in liver. Whilst in late pregnancy, IGF-I concentration decreased because of the decline in both liver and fat mass and at the same time the expression of IGF-I mRNA. In addition, Sferruzzi-Perri et al. (2011) cleared that the main IGF-I sources in pregnant rabbits are, all the body tissues (fat and liver) that increased in mass in parallel with increasing body mass.

These alterations in IGF-I level may consider as a factor that change the maternal endocrine system such as steroid hormones to support pregnancy. As mentioned by Sferruzzi-Perri et al. (2011) and Restiad et al. (2017) this hormone has the ability in enhances P4 secretion from placenta and stimulate estradiol production from ovary. In the current study, IGF-I was negatively correlated with both P4 and E2 (-0.21 and $-0.15, \mathrm{P}<0.05$, respectively) and positively with PRL $(0.002, \mathrm{P}<0.05)$. In the same context, this hormone binds with rabbit embryonic coats (that consist of four layers formed by granulosa cells, oviduct, uterine secretions and the embryo itself) at day three of pregnancy via specific binding proteins, to help the embryo in development (by 83\%). This hormone cannot cross placenta in sufficient quantities, so its effects on fetal growth is indirect effect via its impact on enhances maternal metabolism, nutrient partitioning and 
development of placenta (Sferruzzi-Perri et al., 2011), as well as increases embryonic diameter and cell proliferation (Herrler et al., 1998).

Our current study revealed that, on kindling day, IGF-I level was insignificantly elevated than that during late pregnancy at days 21 and 28. During the second half of pregnancy, IGF-I concentration varied between 114.5 to 136.8 $\mathrm{ng} / \mathrm{ml}$. According to Bielohuby et al. (2014) who stated that, few studies determined concentration of IGF-I in rabbits and it is need further evaluation to describe the changes in IGF-I level in rabbits. Therefore, circulating IGF-I in rabbits varied widely among studies. Our current level is comparable to that (149 ng/ml) reported by Costa et al. (1998). In contrast, the present level is much lower than that $371 \mathrm{ng} / \mathrm{ml}$ (Thakur et al., 2000) and that $285.8 \mathrm{ng} / \mathrm{ml}$ (Bielohuby et al., 2014). Also, our finding completely disagree with that of Alfonso (2016) who stated that, IGF-I level in pregnant rabbits increased gradually with pregnancy advancement recording its lower level $(200 \mathrm{ng} / \mathrm{ml})$ at day 14 and the highest levels were at days 21 and 28 (290 and $300 \mathrm{ng} / \mathrm{ml}$, respectively).

Thyroid hormones: There were no significant $(\mathrm{P}>0.05)$ differences in $\mathrm{T} 4$ and $\mathrm{T} 3$ levels among gestation days. Levels of $\mathrm{T} 4$ and $\mathrm{T} 3$ progressively and insignificantly $(\mathrm{P}>0.05)$ increased with the advancement of pregnancy from low levels at day 14 to the high levels at day 28 (Table 2 and Figure 2). Therefore, concentrations of T4 and T3 increased during the third period of pregnancy than that at the mid gestation. The present trend agrees with that of Cardinalli et al. (2009) who recorded increases in T3 level during the days 21 and 27 of rabbit pregnancy. On delivery day, T4 level slightly reduced than that at late pregnancy. Whereas, T3 level insignificantly $(\mathrm{P}>0.05)$ dropped to the minimal level than that observed at all gestational days (Figure 2). During the second half of pregnancy, concentrations of T4 and T3 hormones ranged between 36.0 to 39.20 and 1.9 to $2.2 \mathrm{ng} / \mathrm{ml}$, respectively. As expected, there was a positive correlation $(0.162 ; \mathrm{P}<0.05)$ between $\mathrm{T} 4$ and $\mathrm{T} 3$ hormones.

The peripheral T4 is converted to the bioactive form (T3), and this conversion is one of the factors that affecting the bioavailability of thyroid hormones for the target tissues. The other factors are, releasing thyroid stimulating hormone, activity of hypothalamus-pituitary axis and the ability of thyroid hormones to bind with their receptors to activate the cellular process (Forhead and Fowden, 2014). During pregnancy, the maternal levels of thyroid hormones are very important for the fetus growth. Rabbits placenta is characterized with its highly permeability for thyroid hormones (via their binding protein receptors such as Transthyretin Receptor, TTR), because if there is any deficiency in fetal thyroid hormones the dam can compensate this deficiency and help them to grow well (Forhead and Fowden, 2014). Thyroid hormones are considering as growth stimulator for the fetus, through their direct and indirect actions. The direct one is their impact on fetal metabolism (increasing $\mathrm{O}_{2}$ and glucose consumption) and the indirect through their relationships with the endocrine system, one of these hormones is IGF-I that expressed widely in fetus tissues. These findings, to some extent, support our present positive relationship between maternal T4 and T3 with IGF-I which was +0.17 and +0.25 $(\mathrm{P}<0.05)$, respectively. It is well known that thyroid hormone affected the reproductive functions.

The present study clarified the positive correlation between T4 and both P4 and E2 $(+0.15$ and $+0.09, \mathrm{P}<0.05$, respectively). The same was recorded for the correlation between T3 and P4 which was +0.002 and +0.04 with E2.

\section{Productive performance of NZW rabbit does}

Milk production: The rabbit does lactate for four consecutive weeks and the average of total milk yield (TMY) was $129.94 \mathrm{~g} / \mathrm{d}$. This is in harmony with that of Ashour et al. (2018). During the weeks of lactation, rabbits produced $91.66 \mathrm{~g} / \mathrm{d}$ in the first week (Figure 3). Then, the produced milk continued in increasing reaching to the maximum amount $(185 \mathrm{~g} / \mathrm{d})$ at the third one. At the fourth week, the DMY declined to $113.11 \mathrm{~g} / \mathrm{d}$, this reduction attributed to MG involution and the decline in hormones level, mainly PRL. Furthermore, at end of lactation, the kits stopped suckling, which stimulates milk secretion via the sending signals to release oxytocin (Neville et al., 2002).

The data revealed a negative correlation between average of TMY and both P4 and E2 (- 0.21 and $-0.04 ; \mathrm{P}<0.05$, respectively). As mentioned previously by Brisken (2002) and Neville et al. (2002), P4 hormone has an important role in proliferation phase of alveolar morphogenesis. However, it has an inhibition effect on milk secretion during lactogenesis 1. Additionally, they cleared that $\mathrm{P} 4$ receptors in MG are consider absent during lactation and returned to be highly expressed at stage of MG involution. The same was for E2 hormone that caused a decrease in milk production and found to be as stimulator factor for MG involution (Neville et al., 2002). Furthermore, average of TMY was positively associated with the T4, T3, IGF-I and PRL hormones $(0.22,0.09,0.01$ and $0.39 ; \mathrm{P}<0.05$, respectively). During the transition period (from late pregnancy and lactation), the activity of enzyme five deiodinase (that covert the T4 hormone to the active form T3) is decreased in liver and increased in MG cells and found to be correlated with lactation intensity (Capuco et al., 2008). Also, during the transition period, thyroid hormones are necessary for galactopoietic responses to PRL (Capuco et al., 2008). The PRL hormones as described previously, increased at late pregnancy (stimulated by rising level of E2) and the expression of PRL receptors mRNA is increasing about 4-10 fold between late pregnancy and the day of kindling, because its importance for lactogenesis 2 (Neville et al., 2002). 


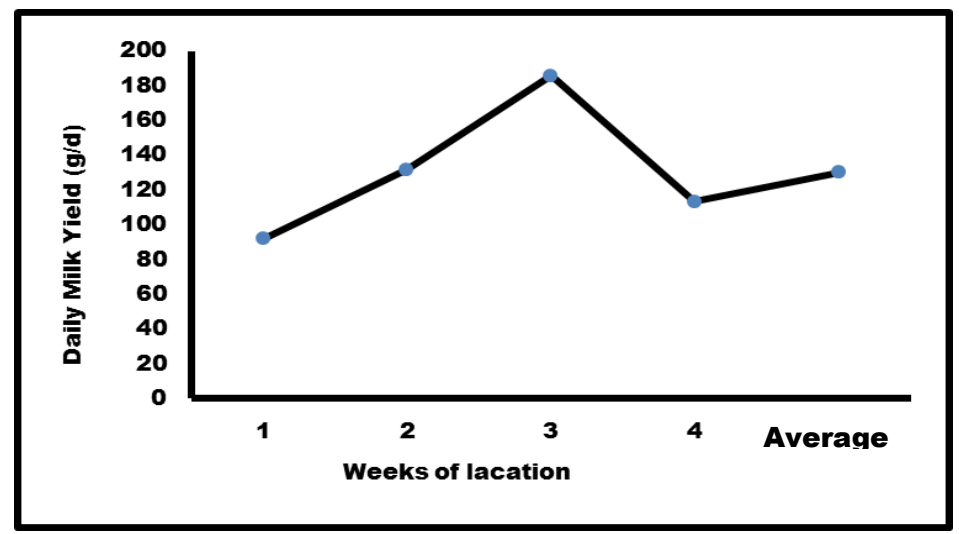

Figure 3. Daily milk yield in New Zealand White rabbit does throughout the lactation period.

Litter size and weight: At birth, the average of litter size (LS) was 6.33, this is closely to those reported by Kelden et al. (2017) and Ashour et al. (2018) who found that LS at birth was 6.8 and 5.67 in rabbit pups. The average of pup's birth weight was $325.56 \mathrm{~g}$, which is mainly associated with their LS. In the present study the LS at weaning was 4.64, which was lower than that recorded at birth, and the average of BW increased eight folds higher than that at birth and reached to 2621g (Table 3). This is agreeing with Ashour et al. (2018) who found that LS and LW were 4.33 and $2261 \mathrm{~g}$, respectively. Furthermore, there was a positive relationship $(0.03,0.13$ and $0.19 ; \mathrm{P}<0.05)$ between LS and P4 (P4 has a role in helping the fetus in implantation, as mentioned previously), E2 and PRL, respectively. Moreover, a negative correlation between LS and T4, T3 and IGF-I (- 0.35, - 0.17 and $-0.25 ; \mathrm{P}<0.05$, respectively) was recorded.

The BW is often used as a proxy for fetal growth and development as well as for fetal nutritional status. The present data recorded that, BW was negatively correlated with P4, E2 and T4 (- 0.21, - 0.08 and -0.29 ; P<0.05, respectively). Medici et al. (2013) supported our finding and stated that, when the dam had higher free T4 during early pregnancy this will lead to lower fetal growth and birth weight. Furthermore, BW was in a positive link with T3, IGF-I and PRL (+0.18, 0.27 and +0.29 ; $\mathrm{P}<0.05$, respectively) this may attribute to both hormones (T3 and IGF-I) which considered as growth stimulator and enhances fetal growth and nutrient partitioning as mentioned previously by Sferruzzi-Perri et al. (2011) and Forhead and Fowden (2014). To the best of our knowledge, most of the research articles have been studied the impact of some feed additives or specific treatment on hormonal changes during pregnancy period such as Kelden et al. (2017). Also, few research articles concerned to clarify the changes of these hormones such as González-Mariscal et al. (2009).

In our study, we concerned to display and describe the changes in reproductive and metabolic hormones during pregnancy period in relation to doe's productivity. In addition, we recommend to give great attention for the female rabbit reproduction and understand deeply all the physiological factors during pregnancy period and their impact on milk production which is the main and nourishment source for the new born that depends on dam milk for about 18 days. In order to breed them in right way and gain the good return through LS and LW that considered the main economical traits in rabbit farming.

Table 3. Averages of litter size and litter weight from birth until weaning day in New Zealand White rabbit.

\begin{tabular}{lcc}
\hline Kits performance & Average & Standard deviation \\
\hline At birth & & 0.86 \\
$\quad$ Size (No) & 6.33 & 48.95 \\
Weight (g) & 325.56 & 1.00 \\
At weaning & & 408.87 \\
$\quad$ Size (No) & 4.67 & \\
$\quad$ Weight (g) & 2621.00 & \\
\hline No = Number & &
\end{tabular}

\section{CONCLUSION}

The current study confirmed the relationship between the hormonal changes and rabbit productivity. However, further studies are urgently needed to verify our results and better understanding of reproductive rabbit's doe to achieve higher economical return. 


\section{DECLARATIONS}

\section{Author's contributions}

Dr. Gamal Ashour (Professor of Animal Physiology) designed the plan of study and providing the experimental animals and tools, writing and revision of the research article, Dr. Samah Mohamed Abdel-Rahman applied the particle part of the study, laboratory and statistical analysis and tabulation of the data.

\section{Competing interests}

The authors have no competing interest, and we are with respect to this search and in agreement with each other. In addition, we have no conflict with authorship or article publication.

\section{Consent to publish}

All the authors approved and agreed to publish the manuscript

\section{REFERENCES}

Al-Atawi FS, Mohammed AH, Arjumand S, Warsy AS and Babay ZA (2004). Leptin concentration during different trimesters of pregnancy and its relation to other pregnancy hormones. Saudi Medical Journal, 25: 1617-1622.

Alfonso CN (2016). Effect of feed restriction in a rabbit line selected for growth rate on reproductive performance: Ovulation induction, oocyte quality, embryo transfer and fetal loss. Ph.D. Thesis, University of Politecnica De Valencia, Spain, pp. 37 -65.

Ashour G, Abdel-Rahman SM, Morsy WA, Abdel- Azeem NM and Barakat SA (2018). Physiological, reproductive and productive performance of rabbit does as influence by N-acetylcysteine administration. Egyptian Journal of Rabbit Science, 28: 63-92

Bielohuby M, Sayyed HZ, Jenny M, Wirthgen E, Katja W, Mohaddeseh TK, Sadat ZA, Robert IW, Andreas H, Mario T, Richard JR and Martin B (2014). Validation of serum IGF-I as a biomarker to monitor the bioactivity of exogenous growth hormone agonists and antagonists in rabbits. Disease Models and Mechanisms, 7: 1263-1273. DOI:10.1242/dmm.016519.

Bostanci MS, Merih B and Zuhal AK (2012). The effects of ascorbic acid on the estrogen/ progesterone levels in the isolated rabbit uterine muscle. Journal of Clinical Gynecology and Obstetrics, 1: 63-66. DOI: http://dx.doi.org/10.4021/jcgo47w.

Brisken C (2002). Hormonal control of alveolar development and its implications for breast carcinogenesis. Journal of Mammary Gland Biology and Neoplasia, 7:49-66. DOI: 0.1023/A:1015718406329.

Capuco AV, Connr EE and Wood DL (2008). Regulation of mammary gland sensitivity to thyroid hormones during the transition from pregnancy to lactation. Society for Experimental Biology and Medicine, 1309 - 1314. DOI: 10.3181/0803-RM-85.

Cardinali R, Dal Bosco A, Castellini C and Brecchia G (2009). Serum level of hormone and metabolites in pregnant rabbit does. Italian Journal of Animal Science, 8: 778-780. DOI:10.4081/ijas. 2009.s2.778.

Costa C, Solanes G, Visa J and Bosch F (1998). Transgenic rabbits overexpressing growth hormone develop acromegaly and diabetes mellitus. FASEB Journal, 12: 1455-1460. https://DOI.org/10.1096/fasebj.12.14.1455

Duncan DE (1955). Multiple range and Multiple F test. Biometrics, 11: 1-42.

Forhead J and Fowden AL (2014) Thyroid hormones in fetal growth and prepartum maturation. Journal of Endocrinology, 221: 87103. DOI: $10.1530 / \mathrm{JOE}-14-0025$

Fortun L, Prunier G, Bolet F and Lebas A (1999). Physiological mechanisms involved in the effects of concurrent pregnancy and lactation on foetal growth and mortality in the rabbit. Journal of Livestock Production and Science, 60: $229-241$. DOI:https://DOI.org/10.1016/S0301-6226(99)00096-2.

Garfield R, George S and Kristof C (1998). Endocrine control of parturition. In: “The Endocrinology of Pregnancy”, Edited by: F. W. Bazer Humana Press Incorporation, Totowa, New Jersey., pp. 407 - 430.

González-Mariscal G, Gallegos JA, Sierra-Ramírez A and Garza Flores J (2009). Impact of concurrent pregnancy and lactation on maternal nest building, estradiol and progesterone concentrations in rabbits. World Rabbit Science, 17: 145 - 152. DOI: $10.4995 /$ wrs.2009.654.

Herrler A, Claudia A K and Henning MB (1998). Insulin and insulin-like growth Factor-I promote rabbit blastocyst development and prevent apoptosis. Biology of Reproduction, 59: 1302-1313.

Kelden MM, Soetanto H, Kusmartono A and Kuswanto A (2017). Concentration of progesterone and prolactin hormones and milk production of New Zealand White rabbits doe fed moringa leaves meal. Mediterranean Journal of Social Sciences, 8: 79 - 85. DOI:10.5901/mjss. 2017.v8n3p79.

Kirat D, Abdel Hamid NE, Mohamed WE, Hamada M and Shalaby SI (2015). Leptin gene expression in rabbits during pregnancy and fetal life. International Journal of Biology, 7: 113-125. DOI: 10.5539/ijb. v7n2p113.

Lebas F (2004). Reflections on rabbit nutrition with special emphasis on feed ingredients utilization. In: Becerril, C.M. and Pro, A. (Editors) Proceedings of the 8th World Rabbit Congress, Puebla. Colegio de Postgraduados, Montecillo, Spain, pp. 686-736.

Medici M, Timmermans S, Willy V, Keizer-Schrama MP, Vincent WW, Albert H, Herbert H, Yolanda B, de Rijke H, Jacoba J, Bonger S, Theo J V, Robin PP and Eric APS (2013). Maternal thyroid hormone parameters during early pregnancy and birth Weight. Journal of Clinical Endocrinology and Metabolism, 98 :59-66. DOI: 10.1210/jc.2012-2420.

Neville MC, Thomas BM and Isabel F (2002). Hormonal regulation of mammary differentiation and milk secretion. Journal of Mammary Gland Biology and Neoplasia, 7: 49 - 66. DOI: 10.1023/A:1015770423167 
Restiadi TI, Imam M, Suzanita U, and Sri M (2017). The effect of insulin-like growth Factor-I of pregnant crossbred mare serum and insulin-like growth Factor-I recombinant mouse on estrous cycles and litter sizes of mice (Mus musculus). The Veterinary Medicine International Conference, pp 175-188. DOI 10.18502/kls. v3i6.1126.

Sferruzzi-Perri NA, Owens JA, Pringle KG and Roberts CT (2011). The neglected role of insulin-like growth factors in the maternal circulation regulating fetal growth. Journal of Physiology, 589: 7-20. DOI: 10.1113/jphysiol.2010.198622.

Szendrő Zs, Matics Zs, Brecchia G, Theau-Clément M, Nagy Z, Princz Z, Biró- Németh E, Radnai I and Nagy I (2010). Milk production of pseudopregnant and multiparous does. World Rabbit Science, 18: 77 - 82. Doi:10.4995/wrs.2010.18.10.

Thakur A, Sase M, Lee JJ, Thakur V and Buchmiller TL (2000). Ontogeny of insulin-like growth factor -1 in a rabbit model of growth retardation. Journal of Surgery Research, 91: 135-140.

Wahab A, Hamayun K, Shakoor A, Muhammad SQ, Younas M Sirzamin K, Umar S and Muhammad KS (2016). Biochemical profile of local rabbits (Oryctolagus cuniculus) during successful pregnancy under backyard production system. Pakistan Journal of Zoology, 48: 625-630.

XLSTAT (2018). Statistical Software for Excel. https://www.xlstat.com/en/. htm ; Internet; accessed 3 December 2018. 28 West 27 th Street, Suite 503 New York, USA, 10001. 